\title{
Role of Coconut Oil Pulling On Oral Health - An Overview
}

\author{
Fizza Saher ${ }^{1}$ \\ BDS \\ Mervyn Hosein ${ }^{2}$ \\ FDS RCS, FDS RCSE, FFDRCSI \\ Jabbar Ahmed ${ }^{3}$ \\ BDS
}

\begin{abstract}
Oil pulling (extended mouth swishing) is a long-established ancient herbal practice that includes swishing of oil for a prolonged period in the mouth for maintaining better oral environment and providing systemic healthy effects. There are number of edible oils which are used in this therapy but the scientific evidence is limited. Recent literature shows that coconut is one of the most popular pulling oil amongst all. Coconut oil is effective against many oral and systemic conditions and also in bacterial and fungal infections because of the presence of lauric acid which is a major fatty acid component. This article reviews the literature regarding the mechanism, composition, benefits and scientific clinical studies related to coconut oil pulling therapy on oral health.

KEY WORDS: oil pulling, coconut oil, lauric acid, monolaurin

HOW TO CITE: Saher F, Hosein M, Ahmed J. Role of coconut oil pulling on oral health - an overview. J Pak Dent Assoc 2018;27(3):94-99.

DOI: https://doi.org/10.25301/JPDA.273.94

Received: 17 April 2018, Accepted: 18 May 2018
\end{abstract}

\section{INTRODUCTION}

$\mathrm{O}$ ral health correlates with systemic health and maintaining oral health is very important as oral cavity is considered a reflection of the general well being of human body. ${ }^{1}$ Unnecessary use of antibiotics, increasing microbial resistance and toxicity has forced scientists to research on natural herbal products. ${ }^{2}$ Hence, the search for alternative therapies to replace the toxic effects of allopathic medicine has been increased nowadays. ${ }^{3}$ In these current years Complementary and Alternative Medicine (CAM) has gained recognition over conventional allopathic medicine on the grounds that the practices and products used are natural and safe. ${ }^{4}$ The CAM is highly recommended due to the advantages of being cost effective, safe and giving the freedom of self-treatment without having any harmful effects. ${ }^{5}$ Ayurveda is an ancient and well known modality of CAM which is defined as "The system of traditional medicine native to the Indian subcontinent and is practiced in other parts of the world as a form of alternative medicine". ${ }^{6}$ Ayurveda emphasize mainly on the prevention of different kind of systemic diseases rather than curing the pathological problems or symptoms. ${ }^{7}$

1. Lecturer and M.Phil candidate Department of Oral Biology Ziauddin College of Dentistry Karachi.

2. Head of Department Department of Oral Biology Ziauddin College of Dentistry Karachi.

3. Lecturer and M.Phil candidate Department of Pharmacology Ziauddin College of Medicine Karachi.

Corresponding author: "Dr. Fizza Saher" < drfizzajabbar@gmail.com >
According to World Health Organization around $80 \%$ of the population across the globe still depends upon these traditional alternative therapies for their health care. ${ }^{8}$ This system is around 5000-year-old which uses specific herbs and minerals for the treatment of various diseases and the plants and herbs which are used in the Ayurvedic medicine have been proven to be harmless and efficient since the ancient times. ${ }^{9}$

Oil pulling is a well known ancient herbal procedure that includes prolonged swishing of oil in the oral cavity to enhance better oral environment. It is a natural remedy that has been practiced for centuries in sub-continent specially in India as a holistic Ayurvedic technique which is mentioned in the text books written by Charaka and Sushrutha. ${ }^{10}$ Oil pulling is not a new concept because way back around 3000BC oil pulling has been discussed in Ayurvedic texts with the names of Kavala or Gandusha and it has been beneficial for about 30 different illnesses including diabetes, asthma, headache and migraine. ${ }^{9,11}$ In Russia the idea of oil pulling was renewed by Dr. Karach during the 1990's. ${ }^{6}$ Dr. Med. Karach mentioned about this extraordinary way of treatment in a conference at the Academy of Sciences of UDSSR. He spoke about various different pathologies including cardiovascular diseases, digestive troubles and many hormonal disorders which can be treated by oil pulling. ${ }^{12}$

\section{BENEFITS OF OIL PULLING THERAPY}

Oil pulling is currently a well renowned CAM remedy 
for different oral illnesses. ${ }^{13}$ Oil pulling is claimed to reduce the chances of dental caries, bleeding gums, xerostomia, cracked lips and to maintain overall health of the teeth, gums, and jaws. ${ }^{14}$ It also helps in removing bad odor from the mouth and stimulates the taste buds. Oil pulling can be an alternative cleaning method in those patients where brushing is difficult as in mouth ulceration, or in those who have a tendency to gag as in asthmatics and severe cough. ${ }^{15}$ However, a survey was conducted by an Indian daily newspaper "Andhra Jyoti" in1996, on the effects of oil pulling on various diseases in which total 1041 readers were included, out of which $89 \%$ reported healthy beneficial effects and only $11 \%$ did not reported any improvement in the signs and symptoms of illnesses. ${ }^{16}$ The procedure is useful in number of systemic diseases which have been illustrated in Fig $1 .{ }^{17}$

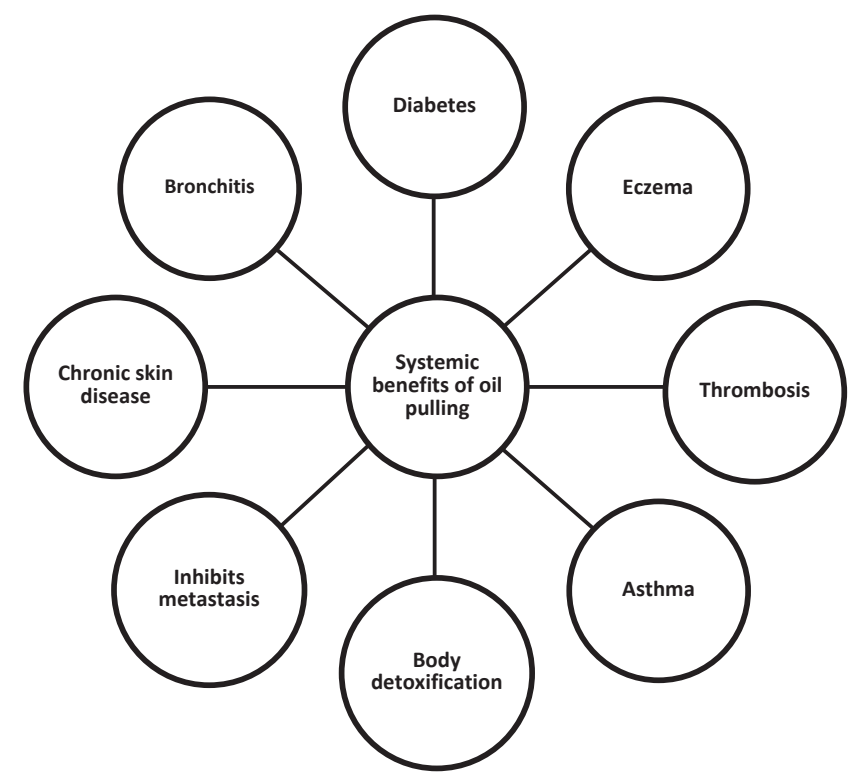

Figure 1

Systemic effects of oil pulling

\section{OIL PULLING THERAPY PROCEDURE}

In oil pulling, a teaspoonful of any kind of oil is swished around the mouth early in the morning preferably before having breakfast, for about 15-20 minutes. The oil is 'pulled' and forced around the oral cavity. If done correctly, oil will become viscous, milky white and thinner. It is then expectorated, the mouth is thoroughly washed with warm saline or normal tap water followed by routine tooth brushing. ${ }^{2}$ If the duration is less than 10 minutes it is not sufficient and if it exceeds more than 20 minutes there are chances of reabsorption of toxins. It can be performed by anyone above 5 years of age, also during pregnancy and menstruation. ${ }^{18}$

\section{COMMONLY USED OILS}

Commonly used oils for oil pulling include: ${ }^{14}$

- Coconut oil

- Sunflower oil

- Sesame oil

- Corn oil

- Palm oil

- Soya bean oil

- Rice bran oil.

\section{IMPORTANCE OF COCONUT OIL}

Coconut oil is derived from the dried kernel of fully ripe coconuts. Grown in tropical regions, it has been among the primary sources of dietary fat for decades. ${ }^{19}$ Coconut oil is commonly and culturally used throughout the sub continent especially in India and Pakistan. ${ }^{20}$ Coconut oil has many healthy effects on hair, skin, cholesterol levels and weight loss. It boosts the immune system and has been used in stress relief. ${ }^{21}$ With added health and nutritional benefits it acts as an anti-inflammatory, immune modulator ${ }^{22}$, moisturizer and wound healer. It shows a potent antimicrobial and anti-fungal activity also. ${ }^{23,24}$

\section{COMPOSITION OF COCONUT OIL}

Coconut oil is made up of medium chain fatty acids whereas other edible oils have long chain fatty acid structure. ${ }^{20,25}$ There are $92 \%$ saturated fatty acids, $6 \%$ monounsaturated fatty acids and $2 \%$ polyunsaturated fatty acids in the composition. The distribution of its total fatty acid content is shown in table 1. Lauric acid, myristic acid

\begin{tabular}{|c|c|}
\hline Fatty acids & \%age \\
\hline Lauric & $44-52$ \\
\hline Myristic & $13-19$ \\
\hline Palmitic & $8-11$ \\
\hline Capric & $6-10$ \\
\hline Caprylic & $5-9$ \\
\hline Oleic & $5-8$ \\
\hline Stearic & $1-3$ \\
\hline Linoleic & $<3$ \\
\hline Caproic & $<1$ \\
\hline
\end{tabular}

Table 1

Fatty acid composition of coconut oil

and palmitic acid are its saturated fatty acids components where as oleic acid and linoleic acid are its only 
monounsaturated and polyunsaturated fatty acids respectively whereas, $\alpha$-tocopherol, $\beta$-tocopherol with $\alpha-, \beta$ and $\gamma$ tocotrienol are the anti-oxidants present in the coconut oil..$^{23}$ The lauric and capric acids hydrolyzes to become monoglycerides named as monolaurin and monocaprin, which are approved by the US Food and Drug Administration (FDA) as non-toxic compounds and used as generally recognized as safe(GRAS) food additive. ${ }^{19}$

\section{MECHANISM OF ACTION}

The actual mechanisms behind oil-pulling therapy are not identified yet. It has been assumed that the plaque aggregation and bacterial adhesion on the tooth surface can be inhibited by the high viscosity of coconut oil. ${ }^{26}$ Moreover, the monolauric and monocapric acids present in the oil has the tendency to penetrate cell membranes and eventually kills the harmful pathogens by inhibiting the enzymes utilized in energy production and nutrient transfer ${ }^{25}$ Another probable mechanism might be due to the alkali hydrolysis of oil by the presence of bicarbonates in saliva known as the saponification process. These soaps might be efficient in removing microbes or plaque materials. ${ }^{25,27}$ Coconut oil has a high saponification index (254.82 $\mathrm{mg} \mathrm{KOH} / 100 \mathrm{~g}$ oil) when compared with other edible oils like soybean and sunflower oil. ${ }^{28}$ It forms a soap like substance called sodium laurate, when lauric acid of the oil gives a chemical reaction with sodium hydroxide and bicarbonates present in saliva, resulting in decreased plaque adhesion and accumulation which enhances cleansing action. ${ }^{27,29}$ Furthermore, the third theory hypothesizes that the antioxidants present in the oil cause detoxification by preventing lipid peroxidation, resulting in an antibiotic-like effect thus helping in the destruction of microorganisms. ${ }^{30}$

\section{DISCUSSION}

The main advantage of oil pulling therapy is its simplicity and a method which is economical for the fact it uses only oil for the swishing for the improvement and maintenance of good oral health with no strict precautions required to follow the regimen. Compared to other detoxification methods, it is effortless and simple. ${ }^{17}$ However researches has been done on the side effects produced by the oil pulling Kuroyama et al reported two cases of exogenous lipoid pneumonia in patients who routinely performed oil pulling with sesame oil. The manifestations of exogenous lipoid pneumonia are fever, weight reduction, cough, dyspnea, chest discomfort, and hemoptysis. Oil might be accidentally suctioned amid oil pulling and it was assumed that if the suctioned oil is microorganism rich, at that point it might bring about appearance of lipoid pneumonia. ${ }^{31}$ Upset stomach has additionally been encountered whereas more scientific data is required to give proof of conceivable side effects. ${ }^{32}$

\section{STUDIES RELATED TO THE EFFECTS OF COCONUT OIL ON SYSTEMIC HEALTH}

Literature suggests the use of coconut oil because of its high saponification value. ${ }^{28}$ In 2017, Mythri assumed the formation of sodium laurate( the main component of soap) which is formed by the interaction of lauric acid found in coconut oil and sodium hydroxide from the saliva during oil pulling causes the cleansing effect and decreased plaque formation in oral cavity. ${ }^{10}$ Furthermore the presence of lauric acid in coconut oil can inhibit the growth of Staphylococcus aureus, Bacillus cereus, Salmonella typhimurium and Escherichia coli at a concentration of 5\% when compared with Ciprofloxacin. ${ }^{33}$ In 2006, Ósk Thorgeirsdóttir et al. investigated the effects of monocaprin acid as a denture disinfecting agent and he reported an increased antimicrobial activity against Candida when it is topically applied. ${ }^{34}$ Likewise, a study done in Nigeria, evaluated 100\% concentration of coconut oil which showed an inhibitory effect on some species of Candida when compared to fluconazole. ${ }^{35}$ Besides this, Verallo-Rowell et al. in 2008 conducted a clinical trial on the antibacterial effects of virgin coconut oil (VCO) against Staphylococcus aureus collected from human atopic dermatitis skins and reported a highly significant decrease in the bacterial count. ${ }^{36}$

According to an animal study done by S. Intahphuak et al. VCO was useful in the reduction of ear and paw edema. The results showed significant anti inflammatory effects when VCO was given in high doses. ${ }^{37}$ Furthermore, in a study by Swee Keong Yeap et al in 2015, mice which were treated with VCO showed increased levels of brain antioxidants and reduction of 5-hydroxy tryptamine with the lowered levels of serum cholesterol, triglyceride, glucose and corticosterone. He proposed that VCO can be used as an anti- stress functional oil. ${ }^{38}$ Horas et al in 2017 conducted a study to evaluate the beneficial effect of VCO on palatoplasty, palatal surgical wound healing. The topical application of virgin coconut oil accelerated wound healing showing an increased number of fibroblast cells appearing in the wound, as well as with fewer pain complaints. ${ }^{39}$

\section{STUDIES RELATED TO EFFECTS OF COCONUT OIL PULLING ON ORAL HEALTH}

Online literature searches in PubMed and Google scholar provided eight scientific articles on oil pulling therapy related to coconut oil which are discussed below: 
Chalke et al in 2017 conducted a trial with 75 subjects having plaque-induced gingivitis on the effects of coconut oil pulling. The clinical parameters such as plaque and gingival index scores were assessed at day 0,15 and 30 . Results showed a significant decrease in pre- and posttreatment scores of plaque and gingival index and they concluded that coconut oil pulling can be used as an adjunctive oral hygiene aid in reducing the plaque formation and subsequent plaque-induced gingivitis. ${ }^{40}$

In 2017 a randomized controlled triple blinded clinical trial was conducted by Varsha et al. to evaluate the effect of oil pulling therapy with pure coconut oil on Streptococcus mutans count. Total thirty patients were included between the ages of 20-23 years and randomly divided into coconut oil, sesame oil and saline groups. The collection of unstimulated saliva before and after oil pulling therapy was done and analyzed for the colony forming units (CFU) pe $\mathrm{rml}$ saliva for S. mutans. There was a statistically significant decrease in the CFU of S. mutans after oil pulling with pure coconut oil showing $P$ value $=0.001$ and also against saline with $\mathrm{P}$ value $=0.039$. The results showed that the oil pulling with pure coconut oil can be effective for maintaining the oral hygiene as it reduces the $\mathrm{S}$. mutans count in saliva. ${ }^{41}$ Another trial was carried out in 2017 by Jithender Nagilla et al., among 40 dental students. The students were randomly assigned to a study group having coconut oil and the control group having a placebo. Plaque levels were assessed on baseline, day 3 and day 7 . The results showed significant decrease in the mean plaque scores and they concluded that oil pulling is effective in controlling plaque levels. ${ }^{42}$

Earlier in 2016, Peedikayil conducted a study on a total of fifty female children aged between 8-12 years for the evaluation of the antibacterial efficacy of coconut oil in comparison with chlorhexidine mouthwash. The treatment regimen (swishing) continued for 30 days with coconut oil or with chlorhexidine. Using the Dentocult SM StripMutans test, the microbial count for S. mutans were recorded on day 1,15 , and 30 . There was a significant decrease in the $\mathrm{S}$. mutans count in the coconut oil as well as in chlorhexidine group. He concluded that the coconut oil has same antimicrobial effects when compared with chlorhexidine mouthwash for the reduction of S. mutans. count. ${ }^{43}$

Another randomized controlled study was done by Kaushik et al in 2016 with a sample size of 60 . The subjects were divided into three groups, Group A: Oil pulling, Group B: Chlorhexidine, and Group C: Distilled water. Saliva samples were collected and cultured on 1st day and after 2 weeks from all subjects. Colonies were counted to compare the efficacy of coconut oil and Chlorhexidine with distilled water and statistically significant reduction in S. mutans count was seen in both the coconut oil pulling and
Chlorhexidine group. ${ }^{44}$

Moreover, an in-vitro study was conducted by Shino et al with the isolation of Candida species in children with Early Childhood Caries. The antifungal activity of coconut oil, $0.2 \%$ chlorhexidine and probiotics on Candida albicans using Disc Diffusion method, when compared with routinely prescribed ketoconazole. Results showed that coconut oil was more effective than probiotics having the mean zone of inhibition $=16.8 \mathrm{~mm}$. The study reported that Chlorhexidine and coconut oil have comparable antifungal effects with ketoconazole. ${ }^{45}$

Another study by Peedikayil was done in 2015 to assess the effect of coconut oil pulling on plaque formation and plaque induced gingivitis. The trial included sixty age matched adolescent teenagers comprising of the age-group between 16-18 years with plaque induced gingivitis who were advised oil pulling for 30 days. Patients were evaluated at baseline, days $1,7,15$ and 30 for periodontal scores. Results showed statistically significant reduction in the plaque and gingival indexes from the 7th day. Peedikayil concluded that coconut oil pulling could be used as an efficient supportive therapy in plaque induced gingivitis. ${ }^{29}$

An in-vitro study in 2011 was done by Thaweboon S. on oil-pulling using coconut oil, corn oil, sesame oil, sunflower oil, palm oil, soya bean oil and rice bran oil. The biofilm models of Streptococcus mutans, Lactobacillus casei and Candida albicans were evaluated on salivary-coated microtiter plates in comparison with the negative and positive controls i.e. $0.2 \%$ chlorhexidine gluconate solution and saline respectively. The author concluded that the coconut oil has a significant antimicrobial activity against $\mathrm{S}$. mutans and $\mathrm{C}$. albicans only. ${ }^{25}$

To date, there are insufficient numbers of scientific studies done on coconut oil pulling itself which can provide the necessary clinical evidence to demonstrate that it reduces the incidence of tooth decay, shows effective teeth whitening or improves overall oral health and well-being. ${ }^{17}$ However, literature suggests that the use of coconut oil in oil pulling therapy may decrease the chances of oral and systemic harmful effects.

\section{CONCLUSION}

In reviewing the literature we feel that adequate research has not been done to assess the benefits of specifically coconut oil pulling in oral cavity, even though there are many studies showing the beneficial effects of coconut oil on general health and oral environment. Available data have shown that coconut oil pulling can significantly reduce plaque and gingivitis and can be used as an effective antibacterial and antifungal agent. Whereas, there is a dire 
need of additional clinical trials which can investigate the effects of monolaurin on oral microorganisms present in dental plaque.

\section{CONFLICT OF INTEREST}

None declared.

\section{REFERENCES}

1. Wade WG. The oral microbiome in health and disease. Pharmacological Research. 2013;69:137-43. https://doi.org/10.1016/j.phrs.2012.11.006

2. Shanbhag VK. Oil pulling for maintaining oral hygiene - A review. J Tradit Complement Med. 2017;7(1):106-9. https://doi.org/10.1016/j.jtcme.2016.05.004

3. Bhardwaj V. Ayurveda and holistic approach in oro-dental care: An overview. SRM Journal of Research in Dental Sciences. 2015;6(3): 181-6.

https://doi.org/10.4103/0976-433X.156218

4. Pan S-Y, Litscher G, Gao S-H, Zhou S-F, Yu Z-L, Chen H-Q, et al. Historical Perspective of Traditional Indigenous Medical Practices: The Current Renaissance and Conservation of Herbal Resources. Evidence-Based Complementary and Alternative Medicine. 2014;2014:20.

5. Pan S-Y, Zhou S-F, Gao S-H, Yu Z-L, Zhang S-F, Tang M-K, et al. New Perspectives on How to Discover Drugs from Herbal Medicines: CAM's Outstanding Contribution to Modern Therapeutics. Evidencebased Complementary and Alternative Medicine : eCAM. 2013;2013:627375.

6. Alaka Hebbar, Vaishali Keluskar, Shetti A. Oil pulling - Unraveling the path to mystic cure. J Int Oral Health 2010;2:10-3.

7. Samal J. The Concept Of Public Health In Ayurveda. International Ayurvedic Medical Journal 2013;1(2):1-5.

8. Parasuraman S, Thing GS, Dhanaraj SA. Polyherbal formulation: Concept of ayurveda. Pharmacognosy Reviews. 2014;8(16):73-80. https://doi.org/10.4103/0973-7847.134229

9. Torwane NA, Hongal S, Goel P, Chandrashekar BR. Role of Ayurveda in management of oral health. Pharmacognosy Reviews. 2014;8(15): 16-21.

https://doi.org/10.4103/0973-7847.125518

10. Mythri H. Oil pulling: A traditional method on the edge of evidence. Dental Hypotheses. 2017;8(3):57-60.

https://doi.org/10.4103/denthyp.denthyp_64_16

11. Lakshmi T, Rajendran R, Krishnan V. Perspectives of oil pulling therapy in dental practice. Dental Hypotheses. 2013;4(4):131-4. https://doi.org/10.4103/2155-8213.122675
12. Fife B. Oil Pulling Therapy: Detoxifying and Healing the Body Through Oral Cleansing: Piccadilly Books, Ltd; 2017.

13. Singh A, Purohit B. Tooth brushing, oil pulling and tissue regeneration: A review of holistic approaches to oral health. J Ayurveda Integr Med. 2011;2(2):64-8.

https://doi.org/10.4103/0975-9476.82525

14. Poonam Tomar, Sudheer Hongal, Manish Jain, Kuldeep Rana, Saxena V. Oil Pulling and Oral Health: A Review. IJSS Case Reports \& Reviews 2014;1(3):33-7.

15. Gunjan Garg, Gopesh Manga, Chundawat NS. AYURVEDIC APPROACH IN ORAL HEALTH \& HYGIENE: A REVIEW International Journal of Ayurveda and Pharma Research. 2016;4(5).

16. Pathak S. Oil pulling therapy in dental practice: A short review. SRM Journal of Research in Dental Sciences. 2016;7(1):33-5. https://doi.org/10.4103/0976-433X.176481

17. Mustafa Naseem, Muhammad Faheem Khiyani, Hiba Nauman, Muhammad Sohail Zafar, Altaf H Shah, Khalil HS. Oil pulling and importance of traditional medicine in oral health maintenance. International Journal of Health Sciences. 2017;11(4).

18. Zaidi MA, Rizvi FJ. Oral hygiene in Ayurveda with special reference to kavala (oil pulling). Heal Talk. 2013;5(5):36-7.

19. Fife B. Coconut cure. 1st edition ed. USA: Piccadilly Books; 2005.

20. Peedikayil FC, S P, Professor AN. OIL PULLING THERAPY AND THE ROLE OF COCONUT OIL. ejournal of dentistry. 2014;4(4):700-2.

21. A.G GK, Raj G, Bhatnagar A, P K PK, Chandrashekar P. Coconut Oil: Chemistry, Production and Its Applications - A Review2009.

22. Illam SP NA, Raghavamenon AC. Polyphenols of virgin coconut oil prevent pro-oxidant mediated cell death. Toxicol Mech Methods. 2017;27(6):442-50.

https://doi.org/10.1080/15376516.2017.1320458

23. Mohd. Shamim Khan QHLaMAK. PHYSICO-CHEMICAL AND PHARMACOLOGICAL PROSPECTIVE OF ROGHAN-E-NARJEEL (COCONUT OIL). International Journal of Pharmaceutical sciences and Research. 2016;7(3):1286-91.

24. Beena Shino FCP, Shyamala R. Jaiprakash,Gufran Ahmed Bijapur, Soni Kottayi, and Deepak Jose. Comparison of Antimicrobial Activity of Chlorhexidine,Coconut Oil, Probiotics, and Ketoconazole on Candida albicans Isolated in Children with Early Childhood Caries: An In Vitro Study. Scientifica. 2016;2016:5 pages.

25. Thaweboon S. NJ, Thaweboon B. Effect of oil-pulling on oral microorganisms in biofilm models. Asia J Public Health. 2011;2: 62-6. 
26. Ahuja DK, Ahuja V. Concept of Oral Hygiene in Ayurveda. International Journal of Ayurvedic Medicine. 2014;5(2):148-53.

27. Parolia A. Oil hygiene. Bdj. 2009;207:408.

https://doi.org/10.1038/sj.bdj.2009.965

28. Srivastava Y, Semwal AD, Sajeevkumar VA, Sharma GK. Melting, crystallization and storage stability of virgin coconut oil and its blends by differential scanning calorimetry (DSC) and Fourier transform infrared spectroscopy (FTIR). Journal of Food Science and Technology. 2017;54(1):45-54. https://doi.org/10.1007/s13197-016-2427-1

29. Peedikayil Faizal C. SP, Narayanan Arun. Effect of coconut oil in plaque related gingivitis - A preliminary report. Nigerian Medical Journal : Journal of the Nigeria Medical Association. 2015;56(2): 143-7.

https://doi.org/10.4103/0300-1652.153406

30. Asokan S, Rathinasamy TK, Inbamani N, Menon T, Kumar SS, $\mathrm{P}$ E, et al. Mechanism of oil-pulling therapy -In vitro study. Indian Journal of Dental Research. 2011;22(1):34-7.

https://doi.org/10.4103/0970-9290.79971

31. Shanbhag VKL. Oil pulling for maintaining oral hygiene - A review. Journal of Traditional and Complementary Medicine. 2017;7(1):106-9.

https://doi.org/10.1016/j.jtcme.2016.05.004

32. King A. BAD SCIENCE: Oil pulling. Bdj. 2018;224:470. https://doi.org/10.1038/sj.bdj.2018.281

33. Febri Odel Nitbania, Juminaa, Dwi Siswantaa, Solikhahb EN. Isolation and Antibacterial Activity Test of Lauric Acid from Crude Coconut Oil (Cocos nucifera L.). Procedia Chemistry 2016;18: 132 - 40.

https://doi.org/10.1016/j.proche.2016.01.021

34. Ósk Thorgeirsdóttir T, Kristmundsdóttir T, Thormar H, Axelsdóttir Í, Peter Holbrook W. Antimicrobial activity of monocaprin: a monoglyceride with potential use as a denture disinfectant. Acta Odontologica Scandinavica. 2006;64(1):21-6. https://doi.org/10.1080/00016350500326245

35. Ogbolu DO, Oni AA, Daini OA, Oloko AP. In Vitro Antimicrobial Properties of Coconut Oil on Candida Species in Ibadan, Nigeria. Journal of Medicinal Food. 2007;10(2):384-7. https://doi.org/10.1089/jmf.2006.1209

36. Verallo-Rowell VM, Dillague KM, Syah-Tjundawan BS. Novel antibacterial and emollient effects of coconut and virgin olive oils in adult atopic dermatitis. Dermatitis : contact, atopic, occupational, drug. 2008;19(6):308-15.
37. S. Intahphuak, Khonsung P, Panthong A. Anti-inflammatory, analgesic, and antipyretic activities of virgin coconut oil. Pharmaceutical Biology. 2010;48(2):151-7. https://doi.org/10.3109/13880200903062614

38. SWEE KEONG YEAP, BOON KEE BEH, NORLAILY MOHD ALI, HAMIDAH MOHD YUSOF, WAN YONG HO, SOO PENG $\mathrm{KOH}$, et al. Antistress and antioxidant effects of virgin coconut oil in vivo. EXPERIMENTAL AND THERAPEUTIC MEDICINE. 2015;9:39-42.

https://doi.org/10.3892/etm.2014.2045

39. Horas Rajagukguka, Sumaryati Syukurb, Sanusi Ibrahimc, Syafrizayantid. Beneficial Effect of Application of Virgin Coconut Oil (VCO) Product from Padang West Sumatra, Indonesia on Palatoplasty Wound Healing. American Scientific Research Journal for Engineering, Technology, and Sciences 2017;34(1):231-6.

40. Chalke S, Zope S, Suragimath G, Varma S, Abbayya K, Kale V. Effect of coconut oil pulling on plaque-induced gingivitis: A prospective clinical study. International Journal of Green Pharmacy. 2017;11(4):750-5.

41. Pavithran V, Krishna M, Kumar V, Jaiswal A, Selvan A, Rawlani S. The effect of oil pulling with pure coconut oil on Streptococcus mutans: A randomized controlled trial. Journal of Indian Association of Public Health Dentistry. 2017;15(3):200-4 https://doi.org/10.4103/jiaphd.jiaphd 2917

42. Nagilla J, Kulkarni S, Madupu PR, Doshi D, Bandari SR, Srilatha A. Comparative Evaluation of Antiplaque Efficacy of Coconut Oil Pulling and a Placebo, Among Dental College Students: A Randomized Controlled Trial. Journal of Clinical and Diagnostic Research : JCDR. 2017;11(9):ZC08-ZC11.

https://doi.org/10.7860/JCDR/2017/26656.10563

43. Peedikayil Faizal BG, Sreenivasan Prathima, John Seena, Chandru T, Remy Vimal. Comparison of antibacterial efficacy of coconut oil and chlorhexidine on Streptococcus mutans: An : An in vivo study Journal of International Society of Preventive and Community Dentistry. 2016;6(5):447-52.

https://doi.org/10.4103/2231-0762.192934

44. Kaushik M, Reddy P, Sharma R, Udameshi P, Mehra N, Marwaha A. The Effect of Coconut Oil pulling on Streptococcus mutans Count in Saliva in Comparison with Chlorhexidine Mouthwash. The journal of contemporary dental practice. 2016;17(1):38-41.

https://doi.org/10.5005/jp-journals-10024-1800

45. Shino B, Peedikayil FC, Jaiprakash SR, Ahmed Bijapur G, Kottayi S, Jose D. Comparison of Antimicrobial Activity of Chlorhexidine, Coconut Oil, Probiotics, and Ketoconazole on Candida albicans Isolated in Children with Early Childhood Caries: An In Vitro Study. Scientifica. 2016;2016:5.

https://doi.org/10.1155/2016/7061587 